\title{
Topectomy versus leukotomy: J. Lawrence Pool's contribution to psychosurgery
}

\author{
Ryan Holland, MD, David Kopel, MD, Peter W. Carmel, MD, MedSci, and \\ Charles J. Prestigiacomo, MD \\ Department of Neurological Surgery, Rutgers New Jersey Medical School, Newark, New Jersey
}

\begin{abstract}
Surgery of the mind has a rather checkered past. Though its history begins with the prehistoric trephination of skulls to allow "evil spirits" to escape, the early- to mid-20th century saw a surge in the popularity of psychosurgery. The 2 prevailing operations were topectomy and leukotomy for the treatment of certain mental illnesses. Although they were modified and refined by several of their main practitioners, the effectiveness of and the ethics involved with these operations remained controversial.
\end{abstract}

In 1947, Dr. J. Lawrence Pool and the Columbia-Greystone Associates sought to rigorously investigate the outcomes of specific psychosurgical procedures. Pool along with R. G. Heath and John Weber believed that nonexcessive bifrontal cortical ablation could successfully treat certain mental illnesses without the undesired consequences of irreversible personality changes. They conducted this investigation at the psychiatric hospital at Greystone Park near Morristown, New Jersey.

Despite several encouraging findings of the Columbia-Greystone project, psychosurgery practices began to decline significantly in the 1950s. The uncertainty of results and ethical debates related to side effects made these procedures unpopular. Further, groups such as the National Association for the Advancement of Colored People and the American Civil Liberties Union condemned the use of psychosurgery, believing it to be an inhumane form of treatment. Today, there are strict guidelines that must be adhered to when evaluating a patient for psychosurgery procedures. It is imperative for the neurosurgery community to remember the history of psychosurgery to provide the best possible current treatment and to search for better future treatments for a particularly vulnerable patient population.

https://thejns.org/doi/abs/10.3171/2017.6.FOCUS17259

KEY WORDS psychosurgery; topectomy; leukotomy; J. Lawrence Pool; Greystone

$\mathrm{T}$ HROUGHOUT psychosurgery's checkered past, there has been a struggle to understand how best to treat patients with psychiatric diseases with a minimum of complications. Optimizing efficacy while maximizing safety was the goal of many surgeons at the time. Though leucotomy was the most common operation offered to this patient population, it was not necessarily considered the best. With this in mind, Dr. J. Lawrence Pool and his colleagues at New Jersey State Hospital at Greystone Park undertook a clinical trial to determine if a topectomy, one of the original methods proposed to treat some refractory psychiatric disorders, was superior to leucotomy. We provide a comprehensive review of how these methods were performed and how the results of the Columbia-Greystone project affected the future of psychosurgery.

\section{Early Psychosurgery}

Psychosurgery consists of operating on the brain for the treatment of certain mental illnesses. ${ }^{3}$ The practice has historically been used across several medical specialties including psychiatry, neurology, and neurosurgery. Its guiding principle is that physical changes to the brain can lead to alterations in emotion and behavior.

One of the most well-known cases of brain lesions leading to changes in personality and behavior is that of Phineas Gage (Fig. 1). In 1848, Dr. John Harlow wrote to the editor of the Boston Medical and Surgical Journal describing how his patient Gage, a 25-year-old railroad foreman, accidentally drove an iron rod through the left side of his face. ${ }^{8}$ After fracturing the floor of the orbit of the left eye, the rod passed through the left frontal lobe and made 


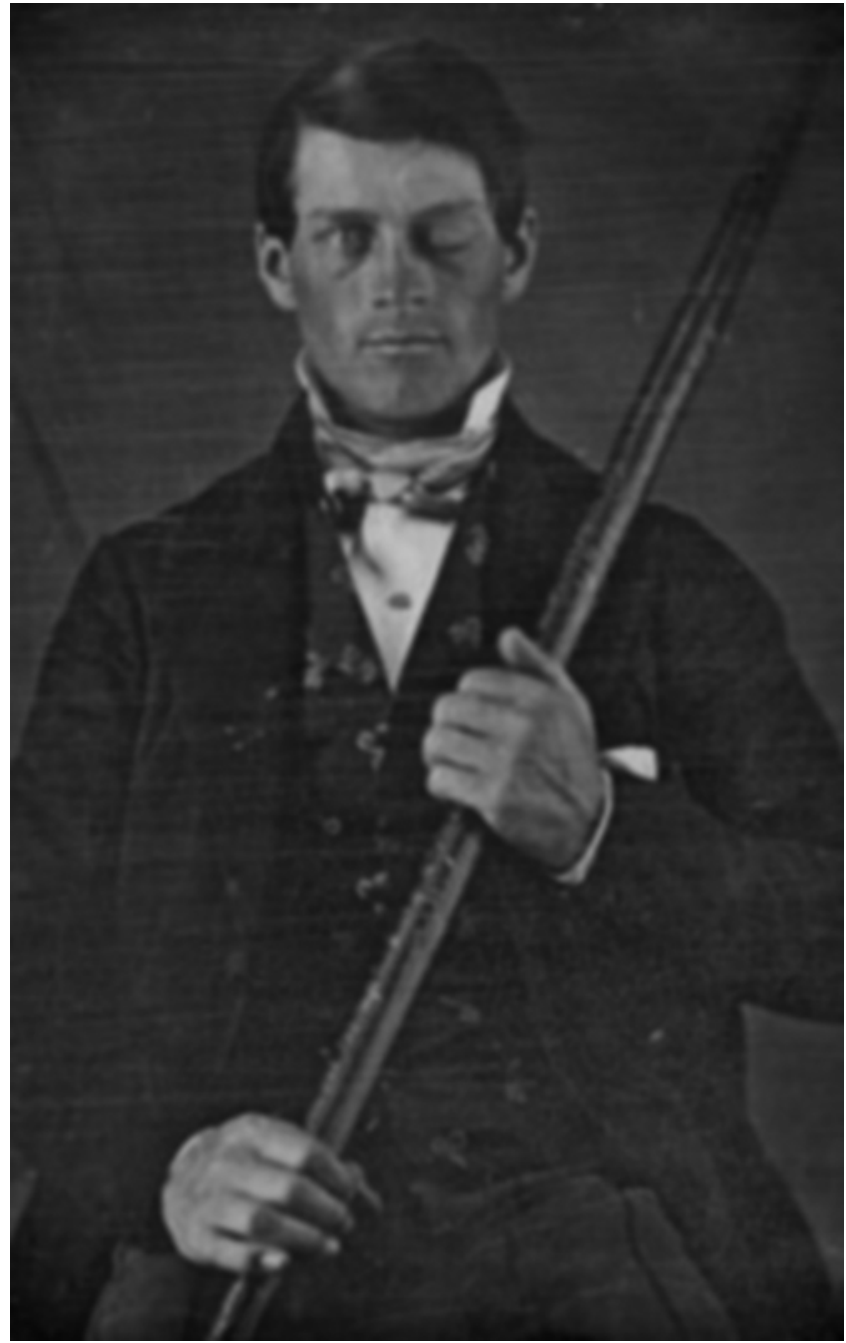

FIG. 1. Phineas Gage holding the tamping iron that injured him. Formally from the collection of Jack and Beverly Wilgus. Presently on exhibition at the Warren Anatomical Museum, Harvard Medical School. Public domain.

its exit at the junction of the coronal and sagittal sutures. Under Harlow's meticulous care, Gage was able to survive the accident. After his recovery, however, he became fitful, irreverent, obstinate, and capricious. Previous to the injury, he had been known as a well-balanced, shrewd, smart businessman. He was so radically changed that his friends and acquaintances said he was "no longer Gage.""

Contrary to Gage's accidental trauma, in 1888, Swiss psychiatrist Gottlieb Burckhardt intentionally lesioned the brain to induce behavioral changes in those with mental illness (Fig. 2). In 1891, he published a case series on topectomy for the treatment of refractory schizophrenia. Burckhardt used a sharp spoon to remove between 1 and $5 \mathrm{~g}$ of cortex from the frontal, parietal, and/or temporal lobes. ${ }^{21}$ The location and amount of excised tissue differed among all of his patients. Following these operations, he stated that his patients were more easily managed and were no longer feared by the attendants and nurses. They also experienced reductions in sudden emotional outbursts. However, his final case resulted in death on the 6th

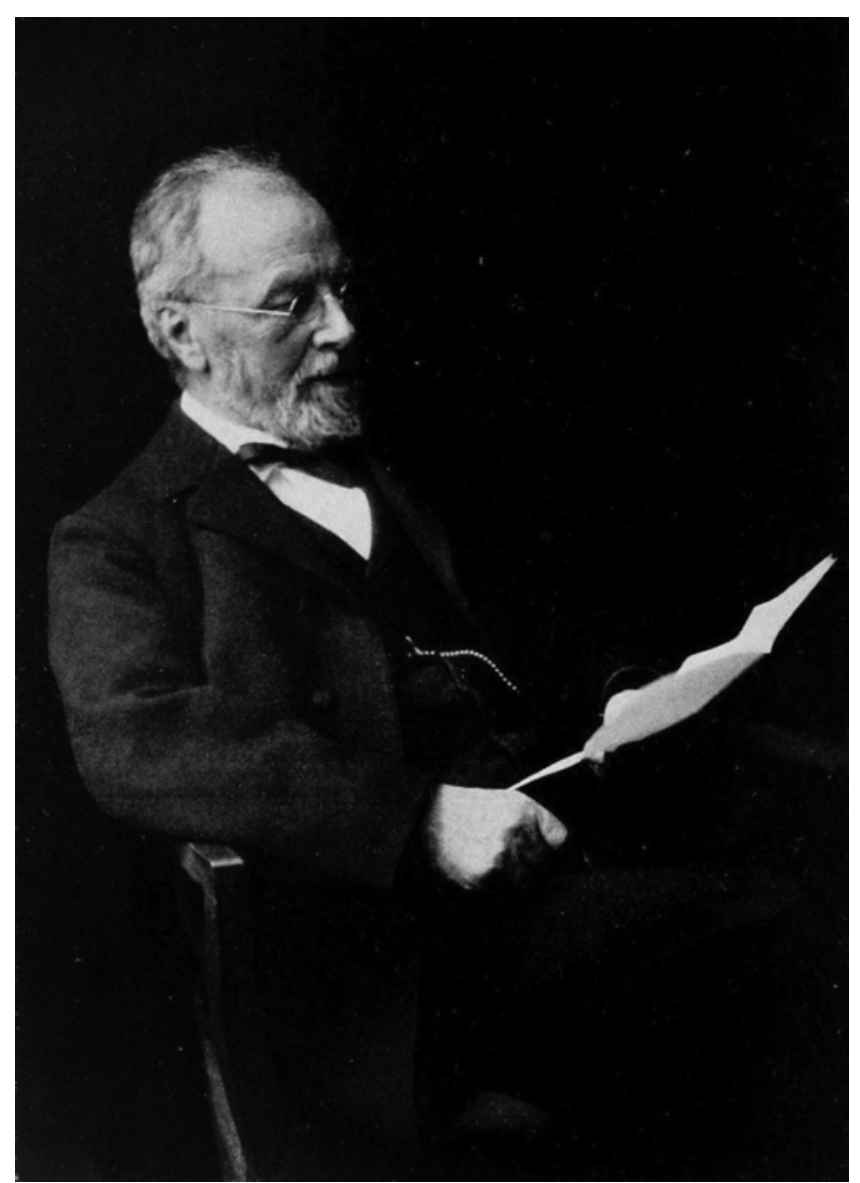

FIG. 2. Gottlieb Burckhardt. From Verhandlungen der Schweizerischen Naturforschenden Gesellschaft, 1907. Public domain.

postoperative day. Autopsy suggested subdural hematoma as the cause of death.

Reaction from the psychological and surgical communities was largely critical. Burckhardt's surgeries were seen as needlessly dangerous with unimpressive results. ${ }^{21}$ He ceased performing these operations following the publication of his case series.

The Portuguese neurologist and early developer of cerebral angiography, António Egas Moniz, completed the first prefrontal leukotomy in 1935 to treat mental illness (Fig. 3). ${ }^{7}$ His inspiration came largely from the works of Yale physiologists John Fulton and Carlyle Jacobsen. Their published works showed changes in chimpanzee affect following the removal of portions of the frontal lobes. The chimpanzees' behavior became more lethargic, and they demonstrated less "incessant activity.", lied heavily on his staff member Almeida Lima to perform these operations since his own hands were deformed by gout. Moniz and Lima first used alcohol injections for the leukotomies but later developed a leukotome that consisted of a cannula with a rotating wire loop at the end, which would separate the white matter. Moniz was satisfied with the results of his first 20 operations, with 7 cases showing improvements, none having worsened, and no deaths. He continued to treat around 80 more patients with these operations throughout his career. ${ }^{7} \mathrm{He}$ won the 


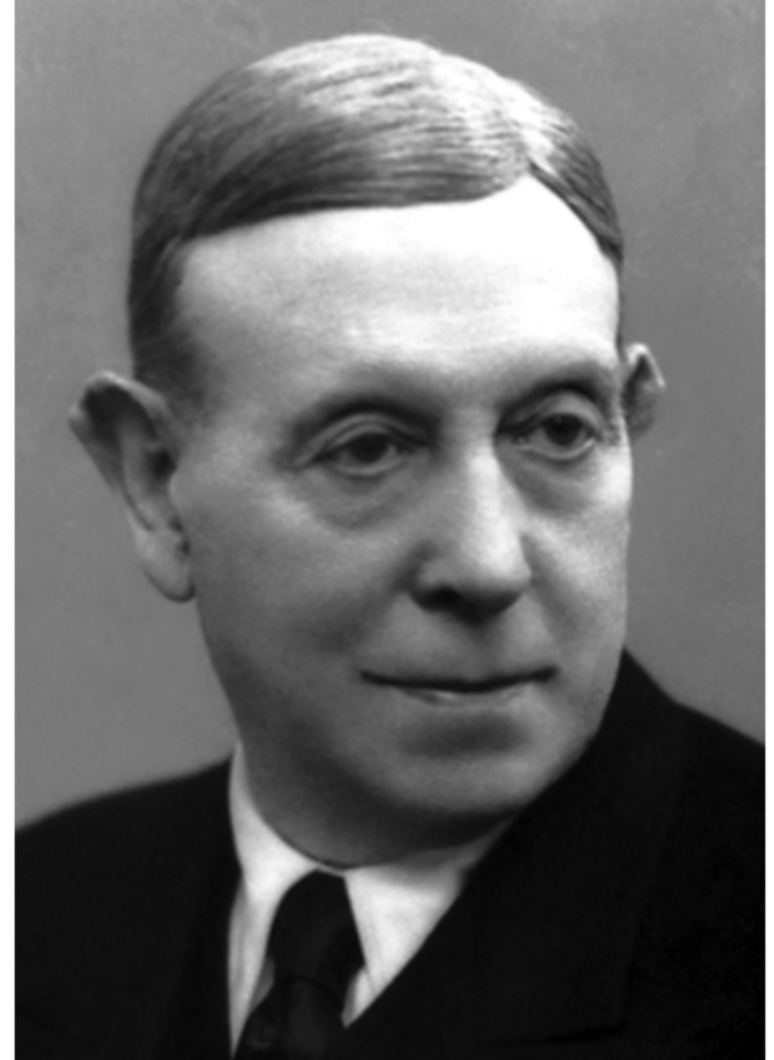

FIG. 3. Dr. António Egas Moniz. PD-Sweden-photo.

Nobel Prize in Physiology or Medicine in 1949 "for his discovery of the therapeutic value of leukotomy in certain psychoses." 14

\section{Leukotomy and Topectomy}

Two years after Moniz's first case series, neurosurgeon James Watts and neurologist Walter Freeman began performing the operations in the United States (Fig. 4). Freeman agreed with Moniz that psychiatric symptoms might be due to abnormal connections in cortical association centers. By severing the connections over a large area, he believed that there might be reintegration of cortical activity along different pathways. Watts and Freeman used the same method as Moniz during their earlier procedures. ${ }^{22}$

Leukotomies were performed for patients with agitated depression, involutional depression, schizophrenia, psychasthenia, psychoneurosis, hysteria, and manic depressive psychosis. He selected his cases based on symptomatology rather than type of disease. Patients presenting with tension, apprehension, anxiety, and agitation were considered candidates regardless of whether the diagnosis was agitated depression, involutional depression, dementia praecox, or other. ${ }^{22}$ Operations were advised if symptoms were of sufficient duration to indicate an unfavorable prognosis, if every recognized method of treatment had been administered unsuccessfully, or if the nature of the psychosis pointed to an unfavorable outlook.

Incisions were made over each frontal lobe $3 \mathrm{~cm}$ lateral to the midline. Bur holes were made $3 \mathrm{~cm}$ in front of

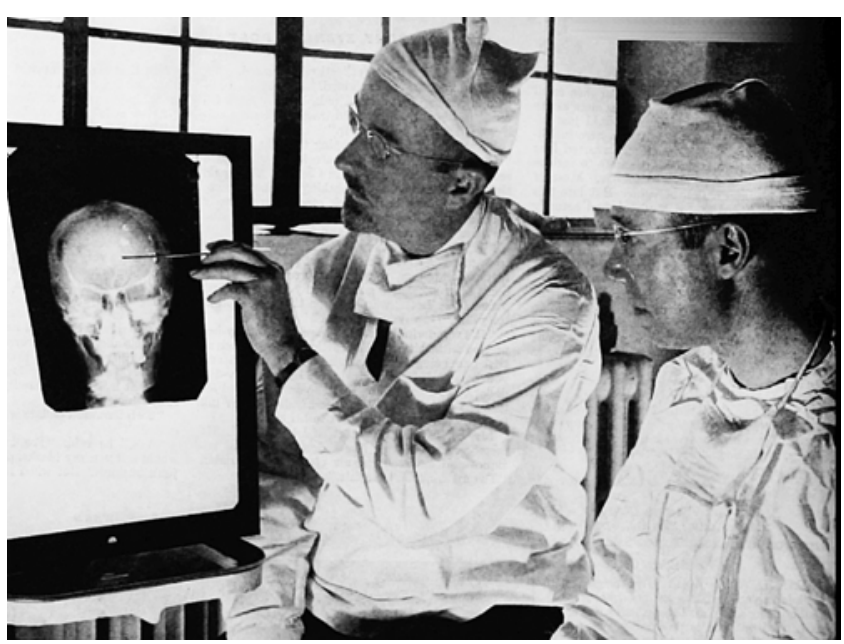

FIG. 4. Dr. Walter Freeman (left) with Dr. James Watts (right). Photograph by Harris A. Ewing for The Saturday Evening Post, pp 18-19, May 24, 1941. Public domain.

the interaural line. The leukotome would be inserted in the anteromedial direction until it reached $4 \mathrm{~cm}$ below the surface of the cortex. The leukotome was rotated, cutting a core of white matter in the prefrontal region $1 \mathrm{~cm}$ in diameter. A second core was cut at a depth of $3 \mathrm{~cm}$ and another at $2 \mathrm{~cm}$. The leukotome was then removed from the brain and placed in an anterolateral direction into the same prefrontal area. Cores were then cut at a depth of 4.5, 3.5, and $2.5 \mathrm{~cm}$. Patients were put to bed in a semi-Fowler's position, and fluid was limited to $1000 \mathrm{ml}$ in 24 hours. Soft diet was started on the 2nd postoperative day, and patients sat up and walked on the 3rd or 4th day. ${ }^{22}$

Following these operations, there was a reduction of tension, apprehension, anxiety, depression, and agitation in most cases. More than half of the patients would speak only when spoken to for a week or 2 after the operation. Some patients had persistent changes in behavior such as emotional flattening, diminished spontaneity, lack of attention, and indifference. Conversely, euphoria and transient perseveration occurred a few times. ${ }^{22}$

In the late $1940 \mathrm{~s}$, Freeman modified his procedure so that bur hole placements would be unnecessary. He used an ice pick perforated through the orbital plate to sever the thalamofrontal radiation. He later designed an orbitoclast after having trouble finding a sturdier leukotome. ${ }^{5}$ Constructed from steel, the orbitoclast was $23 \mathrm{~cm}$ in length and $8 \mathrm{~mm}$ in diameter with the shaft tapering to a blunt point. At $5 \mathrm{~cm}$ from this point, which is the location of maximum stress, the shaft was $5 \mathrm{~mm}$ in diameter. The handle had a hole drilled through it $7 \mathrm{~cm}$ from the top so that measurements could be made to determine the approximate location of the point of the instrument. ${ }^{5}$

The patient's mouth and nose were covered with a towel, and the point of the transorbital leukotome was introduced beneath the upper eyelid, $3 \mathrm{~cm}$ from the midline. The shaft of the instrument was aimed parallel with the bony ridge of the nose, and the handle was struck sharply with a hammer to drive the point through the orbital plate. After the end was inserted $5 \mathrm{~cm}$ past the orbit, the handle of the instrument was drawn far laterally, then returned 
to an angle of $30^{\circ}$ with the parasagittal plane and driven to the 7-cm mark. Allowing $2 \mathrm{~cm}$ for the orbital tissues, the point was then $5 \mathrm{~cm}$ within the white matter of the frontal lobe. To sever the upper portions of the thalamofrontal radiation, the handle was displaced first toward the nose $20^{\circ}-30^{\circ}$ and then laterally $20^{\circ}-30^{\circ} .^{5} \mathrm{Next}$, the deep frontal cut was made. This cut was an oblique incision that severed the fibers of the thalamofrontal radiation as they bend around the anterior horn of the ventricle. In making the deep frontal cut, the handle of the instrument was maintained in the plane $30^{\circ}$ from parasagittal and elevated against the resistance of the orbital plate..$^{5}$

Freeman performed this transorbital leukotomy procedure on more than 2600 patients. He was often dismissive of criticism of these procedures, believing that psychiatrists condemned his operations because the idea of "mutilating the brain" was abhorrent to them. ${ }^{4} \mathrm{He}$ thought that psychiatrists made these arguments simply out of emotion, without providing any evidentiary support. He also believed that neurosurgeons condemned his transorbital procedure because it "[offended] their ideas of neatness and precision" or because they were jealous that psychiatrists were able to perform these operations. ${ }^{4}$

Although Watts and Freeman modified Moniz and Lima's leukotomy procedures, neurosurgeon Dr. J. Lawrence Pool pioneered a topectomy procedure that was more similar to the work of Burckhardt (Fig. 5). Topectomy is a form of cortical ablation developed by Pool in conjunction with psychiatrists R. G. Heath and John Weber for the treatment of mental illnesses. Pool once noted, "'Topectomy' is perhaps a poor term. We coined it in the interests of conciseness, to get away from 'subtotal bilateral prefrontal lobectomy.' Dr W. Penfield of Montreal has used 'bilateral frontal gyrectomy,' which is an equally good or better term." 15

The operation consists of bilateral excision of the cerebral cortex in Brodmann areas 9 and 10 in their rostromedial extent. There was usually a postoperative period of confusion, indolence, and incontinence, but that ceased 2 weeks -2 months following the operation. The operations were conducted to relieve affective or emotional pressure. The patients self-reported that they were able to relax, felt less tense, and felt that they had less pressure in their lives. ${ }^{16}$ In accordance, patients with involutional psychoses, reactive depressions, manic-depressive psychoses, or obsessive-compulsive neuroses reported improvement following the operation. For the schizophrenic group, the responses were split evenly between very good responses and poor ones. Although these patients also experienced diminution of affect or emotion pressure, outcomes relied on the patient's access to resources so that they would be able to reintegrate into society once the affective pressure had been relieved. ${ }^{16}$

Pool initially became interested in the work of Freeman but endeavored to find a more specific approach to frontal lobe operations than was possible via previous lobotomy procedures. He started with the idea of ablating part of Brodmann area 9 because it had been observed by Mettler that behavioral changes in animals were most predominantly associated with bilateral ablation of that area of the cortex. ${ }^{15}$ Pool along with his psychiatric colleague

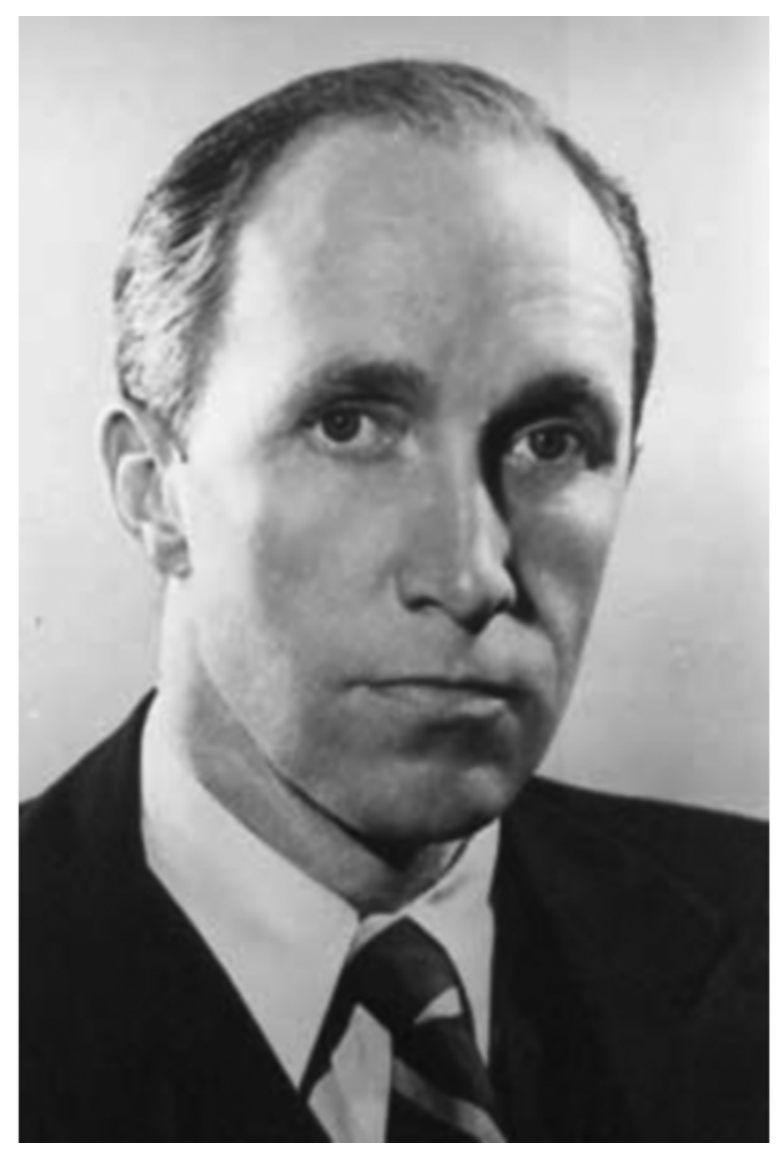

FIG. 5. Dr. J. Lawrence Pool. Reproduced from University Archives, Rare Book and Manuscript Library, Columbia University in the City of New York.

Heath sought to rigorously investigate the effects of these procedures.

\section{Columbia-Greystone Project}

From 1946 to 1947, Pool and Heath performed topectomy on 4 psychotic patients with sufficiently encouraging results to warrant a pilot study of the procedure, which was performed by the Columbia-Greystone Associates in 1947-1948 under the direction of neurologist and neuroanatomist Dr. Fred Mettler. ${ }^{19}$

The Columbia-Greystone Project originated partially from a series of lectures that Mettler gave to the New Jersey Neuropsychiatric Association, which was attended by many staff members of the New Jersey State Hospital at Greystone Park. The hospital served the area from which most of the patients came and whose relatives were interested in having the psychosurgery performed (Fig. 6). Greystone Psychiatric Hospital was ideal because of its large patient population, and Mettler believed it was a serious error to select cases from too small a raw group..$^{13}$

The associates knew from experience and the literature that some patients would improve following psychosurgery. They were mainly interested in determining how to manipulate the causes of these improvements in the most expeditious and least harmful manner. A screening procedure was conducted to eliminate from the operative se- 


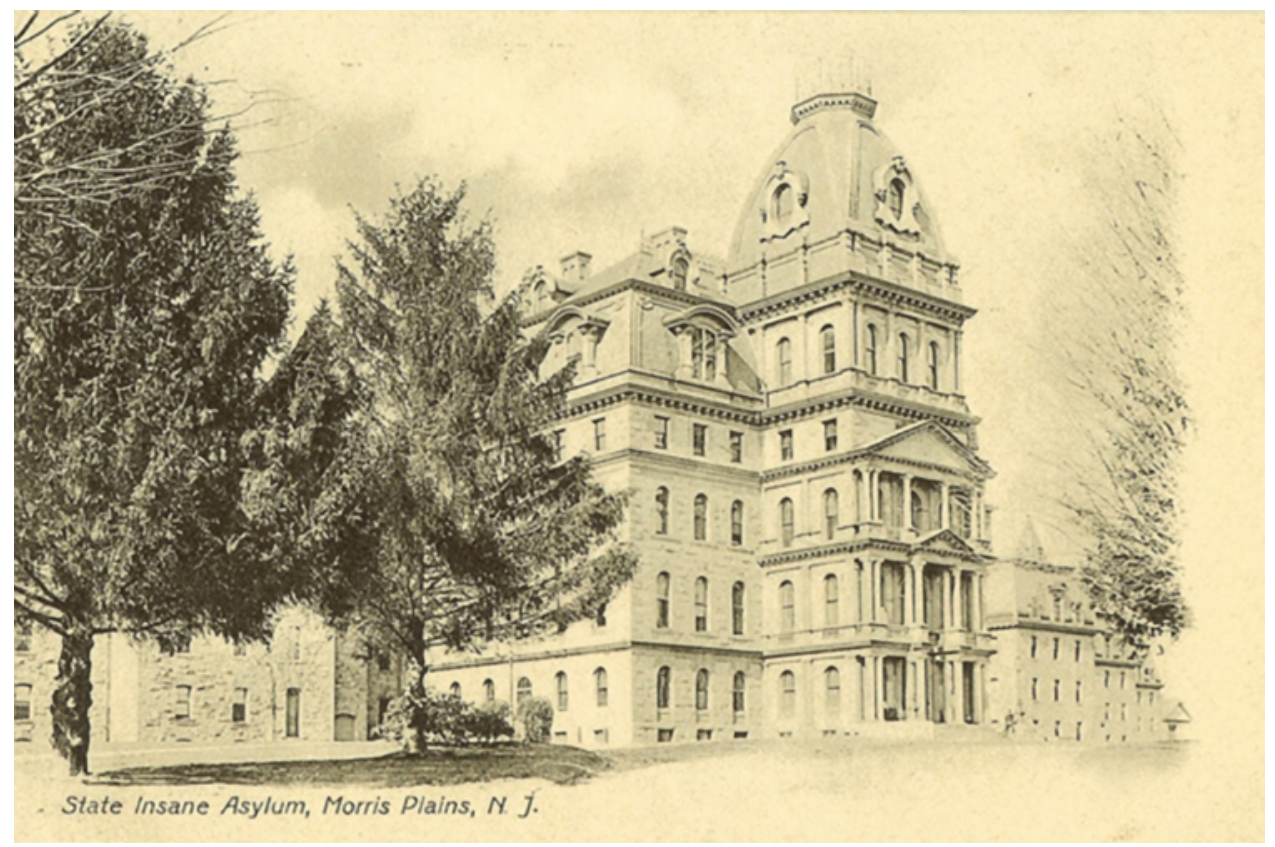

FIG. 6. New Jersey State Hospital at Greystone Park. Postcard from the Greystone Park Psychiatric archives. Public domain.

ries those cases in which spontaneous improvement might occur and cases with patients who were unavailable for psychological testing..$^{13}$ Chosen patients were those who had graduated from grade school in the United States, had been ill for at least 3 years without remission, had received all indicated therapy, and had a presumably satisfactory home to which they might return if they improved. ${ }^{13}$

Permission to operate was obtained from family members. To minimize any possible coercion of relatives to sign the consent, relatives were told that a small percentage of operative patients improve a great deal, most have some degree of improvement, and a few fail to show any improvement. No attempts were made to persuade those who were reluctant to sign the consent. Staff members from the hospital including psychiatrists, social services, occupational therapy, and other staff were aware of the research being conducted. ${ }^{13}$

Prior to 1947 , most of the literature indicated adverse, irreversible personality changes following bilateral excision of frontal lobe cortex. However, these case reports indicated extensive frontal lobe pathology. Pool, Heath, and Mettler believed that bifrontal cortical ablation, if not excessive, might not necessarily lead to significant personality changes.$^{19}$ They chose to conduct this investigation at Greystone Psychiatric Park near Morristown, New Jersey.

In 1872, New Jersey governor, Theodore F. Randolph, announced a plan to appropriate $\$ 100,000$ to erect an asylum on 408 acres of farmland located about 3 miles from Morristown. The area had a robust water supply, stone quarries, and clay beds to produce brick for the institution..$^{10}$ Within 4 years, the project was complete, and the hospital was opened. Dr. H. A. Buttolph, who had been the superintendent of the asylum at Trenton, was named the superintendent of the new institution on June 8, $1876 .{ }^{10}$

The board of managers decided that the patients in the asylum at Trenton who hailed from Atlantic, Cape
May, Cumberland, Salem, Gloucester, Camden, Burlington, Mercer, Ocean, Monmouth, Hunderton, Somerset, and Middlesex counties should remain there. The other patients would be transferred to the state asylum near Morristown..$^{10}$ By August 25, 292 patients had been transferred to the asylum, which had room for 500 patients at the time. In 1893, the institution's name was changed from the "State Asylum for the Insane at Morristown" to "New Jersey State Hospital at Morris Plains." Additional buildings were created to house 750 more patients..$^{10}$ In 1924 , the name was changed to the "New Jersey State Hospital at Greystone Park." The grounds eventually expanded to 1273 acres. By 1949, there were a total of 900 beds. $^{20}$

It was at this location that the Columbia-Greystone Associates orchestrated their research on the efficacy of psychosurgery for the treatment of mental illness. A similar procedure was conducted in all patients undergoing topectomy. Patients were placed supine with the head flexed at about $45^{\circ}$. Anesthetics consisted of sodium pentothal administered intravenously, supplemented by nitrous oxideoxygen by inhalation through an intratracheal tube and local infiltration of the scalp with a $1 \%$ Novocain solution. ${ }^{19}$

A single frontal bone flap was reflected, the dura mater was opened bilaterally, and the relevant cortical area was excised. Each excision began 2-2.5 $\mathrm{cm}$ anterior to the coronal suture at the midline. The size of the removed cortex from each frontal lobe measured $5.5 \mathrm{~cm}$ in the anteroposterior plane, $3.5 \mathrm{~cm}$ in width, and $2 \mathrm{~cm}$ in depth. ${ }^{16}$ Each block of removed cortex weighed $25-35 \mathrm{~g}$ in the fresh state. ${ }^{19}$

This procedure, first performed in 1946, involved the creation of a coronal incision and a single skull flap to expose the patient's frontal lobes bilaterally. ${ }^{17}$ After this, the cortical tissue of the rostromedial frontal lobe was excised until the white matter was reached. In this particular study, the mass of gray matter removed depended on the 
indication for surgery: $30-35 \mathrm{~g}$ were removed from each side for patients with chronic schizophrenia, 20-25 g for patients with obsessive-compulsive disorder or depression, and $15-20 \mathrm{~g}$ for patients with a primary complaint of pain. After a few preliminary surgeries, the investigators believed that the greatest effect could be achieved by focusing on the removal of Brodmann areas 9 and 10.17

The results of the Columbia-Greystone investigation were reported in $1949 .{ }^{13}$ In total, 48 patients were studied with 24 in the operative group and 24 in the nonoperative group..$^{13}$ The surgical group included procedures such as frontal lobe topectomy, venous ligation, and traditional prefrontal lobotomy. ${ }^{13}$ Psychiatric follow-up studies were performed on all patients for 1 year. These studies focused on the patient's social and vocational status, type and intensity of any psychopathology, undesirable personality changes, and prevalence of seizures. ${ }^{13}$

The primary findings of the Columbia-Greystone project were that in the topectomy cases studied, there were no intraoperative mortalities, although topectomy was associated with a higher rate of postoperative seizures than those following traditional lobotomy. Topectomy also caused less dysfunction in emotional and intellectual capacities than lobotomy. It is worth noting that while the psychiatrists, who were the ones assessing emotional and intellectual changes (rather than the neurosurgeons), found significant improvement in $44 \%$ of the patients, these effects were measured by history (including collateral history from the family) and clinical impression. ${ }^{17}$ There is much room for error and bias on the part of the psychiatrists who, along with the patients, were not blinded in this study.

The surgeons often noted that the relevant cortical matter appeared grossly abnormal (firm, atrophic, yellow, and/ or containing abnormal-appearing vasculature); however, microscopic tissue analysis did not show any consistent abnormality in the excised tissue. All patients had normal preoperative electroencephalography (EEG) results, and while most had EEG changes after the operation, these changes disappeared in most patients by the 4 th postoperative month. Other interesting findings included the effects of the surgery on what Pool referred to as the "visceral brain." 18 In particular, after surgery many patients experienced urinary retention that was self-limited. Other temporary changes included salivation, vomiting, diarrhea, incontinence, and changes in gastric motility and acidity. Of the operative patients in the study, 7 had 2 or more seizures after the operation. The seizures were generalized tonic-clonic convulsions with impaired consciousness and without aura or features suggesting a focal onset. Pool postulated that the only factor that significantly increased the chance of developing seizures was excessive use of electrocautery during the operation.

It was found that adjustment outside the hospital was influenced by the relationship between the patient and his or her caretaker parents or spouse among the 8 topectomy patients who maintained their improvement at the end of the 2nd year; Brodmann areas 9, 10, and/or 46 were included in the excisions in 6 of these patients..$^{13}$ Attitude evaluation led to the conclusion that anxiety reduction was the most important underlying change resulting from the surgery.

Of the 11 patients who could eventually be released from Greystone Park, 10 returned to families that appeared to be welcoming. ${ }^{13}$ Of the 10 surgical patients who did not adjust outside the hospital, 3 returned to spouses who did not want them and 5 returned to parents who had an antagonistic relationship with the patient. ${ }^{13}$

\section{Decline of Psychosurgery}

Despite the findings of the Columbia-Greystone project, psychosurgery practices began to decline significantly in the 1950s. ${ }^{2}$ The worldwide spread of psychosurgery had been unevenly distributed, although the United States, Spain, and Italy had earlier acceptance than other European countries. The uncertainty of results and the high risk involved turned psychosurgery into a solution of last resort. Ethical debates surrounding psychosurgery were related to its side effects and uncertainty. The most significant condemnation often came from the practitioners themselves. The fifth annual meeting of the International Society of Psychiatric Surgery was held in 1978, but the following conference was canceled because the members believed that the influence of psychosurgery was fading and that discussions about proper treatment for these patients should take place within the broader psychiatry field. The last documents in the archives of the International Society of Psychiatric Surgery discuss arrangements to include a panel on psychosurgery at the International Congress of Psychiatry.

Further, groups such as the National Association for the Advancement of Colored People and the American Civil Liberties Union condemned the use of psychosurgery, believing it to be an inhumane form of treatment, a condemnation that held particular weight in a time when public participation in the scientific endeavor was a hot topic. ${ }^{1}$ In the face of scrutiny from within the field of psychiatry as well as by the general public, psychosurgery began to fall out of favor.

In 1977, the National Commission for the Protection of Human Subjects of Biomedical and Behavioral Research investigated the use of psychosurgery. The commission ultimately endorsed continued limited use of these procedures. $^{12}$ Currently, neurosurgical procedures for psychiatric disease are reserved for patients whose condition is refractory to pharmacological, psychotherapeutic, or electroconvulsive therapies. Only a patient's psychiatrist can recommend a surgical procedure and must provide detailed documentation regarding the course of therapy and the reasons for any discontinuation of therapy. The patient's family must also express interest in the surgery, and their interests must be directed to the best outcome for the patient.

\section{Conclusions}

The initial intent of psychosurgery was to treat certain psychiatric conditions that were refractory to traditional medical management. Several neurosurgical procedures were created with this purpose in mind. Dr. J. Lawrence Pool attempted to use the scientific method to evaluate the efficacy of psychosurgery. Following a nationwide discussion on the ethics of these operations, the practice of psychosurgery has lost much of its previous popularity. 
Today, there are strict guidelines that must be adhered to when evaluating a patient for psychosurgery procedures. It is imperative for the neurosurgery community to remember both the positive and negative aspects of the history of psychosurgery to provide the best possible treatment to a particularly vulnerable patient population.

\section{Acknowledgments}

We thank Bennet Mueller Stein, MD, for providing significant source material for this article.

\section{References}

1. Casey BP: The surgical elimination of violence? Conflicting attitudes towards technology and science during the psychosurgery controversy of the 1970s. Sci Context 28:99-129, 2015

2. Correia M: Psychosurgery (1974-2014). Withdrawals and revivals. New movements and old inspirations. C R Biol 338:602-606, 2015

3. Freeman W: Psychosurgery. J Natl Med Assoc 42:206-209, 1950

4. Freeman W: Psychosurgery; present indications and future prospects. Calif Med 88:429-434, 1958

5. Freeman W: Transorbital lobotomy: the problem of the thick orbital plate. Am J Psychiatry 108:825-828, 1952

6. Fulton JF, Jacobsen CF, Kennard MA: A note concerning the relation of the frontal lobes to posture and forced grasping in monkeys. Brain 55:524-536, 1932

7. Gross D, Schäfer G: Egas Moniz (1874-1955) and the "invention" of modern psychosurgery: a historical and ethical reanalysis under special consideration of Portuguese original sources. Neurosurg Focus 30(2): E8, 2011

8. Harlow JM: Passage of an iron rod through the head. Boston Med Surg J 39:389-393, 1848

9. Harlow JM: Recovery from the passage of an iron bar through the head. Pub Mass Med Soc 2:329-346, 1868

10. Hurd HM, Drewry WF, Dewey R, Pilgrim CW, Blumer GA, Burgess TJW: The Institutional Care of the Insane in the United States and Canada. Baltimore: The Johns Hopkins Press, 1916

11. Jacobsen CF: Functions of frontal association area in primates. Arch Neurol Psychiatry 33:558-569, 1935

12. Mashour GA, Walker EE, Martuza RL: Psychosurgery: past, present, and future. Brain Res Brain Res Rev 48:409-419, 2005

13. Mettler FA (ed): Psychosurgical Problems. London: Routledge, 2013

14. Nobel Foundation: The Nobel Prize in Physiology or Medicine, 1949. Nobelprize.org. (https://www.nobelprize.org/ nobel_prizes/medicine/laureates/1949/) [Accessed July 5, 2017]

15. Pool JL: Topectomy. Proc R Soc Med 42 Suppl:2-3, 1949

16. Pool JL: Topectomy: a surgical procedure for the treatment of mental illnesses. AMA Arch Neurol Psychiatry 65:105-111, 1951

17. Pool JL: Topectomy; the treatment of mental illness by frontal gyrectomy or bilateral subtotal ablation of frontal cortex. Lancet 2:776-781, 1949

18. Pool JL: The visceral brain of man. J Neurosurg 11:45-63, 1954

19. Pool JL, Heath RG, Weber JJ: Topectomy; surgical technique, psychiatric indications and postoperative management. J Nerv Ment Dis 110:464-477, 1949

20. Rae JW: Morristown: A Military Headquarters of the American Revolution. Charleston, SC: Arcadia Publishing, 2002

21. Stone JL: Dr. Gottlieb Burckhardt-the pioneer of psychosurgery. J Hist Neurosci 10:79-92, 2001

22. Watts J, Freeman W: Psychosurgery: effect on certain mental symptoms of surgical interruption of pathways in the frontal lobe. J Nerv Ment Dis 88:589-601, 1938

\section{Disclosures}

The authors report no conflict of interest concerning the materials or methods used in this study or the findings specified in this paper.

\section{Author Contributions}

Conception and design: all authors. Drafting the article: all authors. Critically revising the article: all authors. Study supervision: Prestigiacomo, Carmel.

\section{Correspondence}

Charles J. Prestigiacomo, East Hanover, New Jersey. email: cjp9@ icloud.com. 